\title{
The controversy over the association between statins use and progression of age-related macular degeneration: a mini review
}

This article was published in the following Dove Press journal:

Clinical Ophthalmology

28 July 2010

Number of times this article has been viewed

\section{Vasileios Peponis' \\ Spyridon E Chalkiadakis \\ Stefanos Bonovas ${ }^{2,3}$ \\ Nikolaos M Sitaras ${ }^{2}$}

'Athens Eye Hospital, 2nd Eye Clinic, Athens, Greece; ${ }^{2}$ Department of Pharmacology, School of Medicine, University of Athens, Greece;

${ }^{3}$ Center for Diseases Control and

Prevention, Athens, Greece
Correspondence:Vasileios Peponis 'Ophthalmiatreio' Athens Eye Hospital, Second Eye Clinic, Eleftheriou Venizelou 26, 10672, Athens, Greece

$\mathrm{Tel}+302103623191$

Fax +302103608660

Email pepbas@yahoo.com
Objective: Age-related macular degeneration (AMD) is the leading cause of blindness in western societies. Statins comprise a class of pharmacological agents that reduce plasma cholesterol levels, and have been shown to prevent progression of atherosclerosis and reduce cardiovascular mortality. The relationship between these medications and AMD has been evaluated in several recent studies. Herein, we examine the current evidence for an association between statin use and risk of AMD.

Methods: Literature database search (Medline, Scopus, and Science Citation Index Expanded) for articles published up to March 2010, using particular search terms.

Results: From the current evidence available, it is not safe to conclude upon the assumption of a protective effect of statins against age-related maculopathy and AMD.

Conclusion: There is a need for large scale prospective studies with a long follow-up period and accurate assessment of AMD to further explore this matter.

Keywords: age-related macular degeneration (AMD), blindness, statin use, controversy

Age-related macular degeneration (AMD) is the leading cause of blindness in industrialized countries. ${ }^{1}$ Though some treatments slow the loss of visual function in later stages of age-related maculopathy (ARM), ${ }^{2,3}$ there is no effective treatment for ARM or for arresting its progression in its earliest phases.

The observation that AMD and atherosclerosis share common risk factors and pathogenetic mechanisms ${ }^{4}$ has led to the development of a hypothesis that is identified as the hemodynamic ${ }^{5}$ and vascular model of the pathogenesis of AMD. AMD is a vascular disorder characterized by impairment of choroidal perfusion of the retinal pigment epithelium (RPE). This model ${ }^{6}$ is now updated to incorporate recently reported evidence ${ }^{7}$ that the changes affecting Bruch's membrane during ageing and AMD involve lipoproteins processed by the RPE. The model proposes that these lipoproteins accumulate in Drusen and in Bruch's membrane because the choriocapillaris does not clear them.

3-Hydroxy-3-methylglutaryl-coenzyme A reductase inhibitors (statins) comprise a class of pharmacological agents that reduce plasma cholesterol levels by inhibiting hepatic HMG-CoA reductase, the rate-controlling enzyme in cholesterol synthesis. In recent years, several researchers have suggested that statins - which are known to be beneficial in vascular disease - also exert protective effects in AMD. It is therefore instructive to systematically review the evidence to date.

\section{Search strategy and results}

We searched the following computer-stored bibliographic databases: (i) Medline, (ii) Scopus, and (iii) Science Citation Index Expanded, for articles published up to 
March 2010. Search terms included: "statin(s)" or "HMGCoA reductase inhibitor(s)" or "atorvastatin" or "cerivastatin" or "fluvastatin" or "lovastatin" or "mevastatin" or "pravastatin" or "rivastatin" or "rosuvastatin" or "simvastatin" combined with "macular degeneration" or "maculopathy". No language restriction was applied.

The Medline search contained 46 records, while 89 and 58 were identified from the Scopus and the Web of Science database, respectively. We scanned titles and abstracts of the articles identified, and excluded those that were clearly irrelevant. We read the full text of the remaining manuscripts to determine whether it contained information on the topic of interest. We also reviewed the reference lists of articles with information on the topic to identify additional relevant studies. In total we reviewed 23 manuscripts of published clinical studies (Table 1).

\section{Pathogenetic models of AMD}

Two main clinical types of AMD exist, referred to as the "dry form" and the "wet form". Blindness is usually associated with the exudative or wet form of AMD. Nonetheless, macular degeneration rarely results in complete blindness. Peripheral vision is usually not affected. Patients with early
AMD may report slightly blurred central vision, difficulty in reading, color and contrast disturbances, and mild metamorphopsia.

The eye tissues affected by AMD are photoreceptors, retinal pigment epithelium (RPE), choriocapillaris (the blood supply to the photoreceptors and the RPE), and Bruch's membrane (a thin vascular intima between the RPE and the choriocapillaris). ${ }^{8,9}$ Prominent extracellular lesions located between the RPE and Bruch's membrane can be either focal or diffuse in form (Drusen and basal deposits, respectively). These changes predispose to the development of late stage ARM, referred to as age-related macular degeneration. It is characterized by geographic atrophy, choroidal neovascularization, pigment epithelial detachment, and fibrous scarring, which can occur in later stages.

Friedman has proposed an interesting theory on the pathogenesis of AMD. He stated that there should be a vascular and hemodynamic model. According to this model, choroidal vascular resistance is increased by decreased compliance of ocular tissues, ${ }^{10}$ as a result of progressive infiltration of the vessels with lipid in atherosclerosis. Moreover, as an extension of the above model, systemic hypertension, as well as subclinical atherosclerosis, increases the risk of neovascular

Table I Demographic data of clinical studies included

\begin{tabular}{|c|c|c|c|c|c|}
\hline Relevant study & $\begin{array}{l}\text { Type of } \\
\text { maculopathy }\end{array}$ & Statins used & Cohort size & Conclusion & Type of study \\
\hline Martini et al & ARM & Simvastatin & 30 & Not protective & Randomized clinical trial \\
\hline Hall et al & Wet and dry AMD & Any agent & 392 & Protective & Cross sectional \\
\hline McCarty et al & Wet and dry AMD & Any agent & 2594 & Protective & Cross sectional \\
\hline Delcourt et al & $\begin{array}{l}\text { ARM and/or Wet } \\
\text { and dry AMD }\end{array}$ & Any agent & 2183 & Not protective & Cross sectional \\
\hline Wilson et al 2004 & Wet and dry AMD & Any agent & 326 & Protective & $\begin{array}{l}\text { Retrospective } \\
\text { consecutive case series }\end{array}$ \\
\hline Klein et al 200I & ARM & Any agent & 2831 & Not protective & Cohort \\
\hline Klein et al 2003 & $\begin{array}{l}\text { ARM and/or Wet } \\
\text { and dry AMD }\end{array}$ & Any agent & 2764 & Not protective & Cohort \\
\hline van Leeuwen et al & ARM & Any agent & 4882 & Not protective & Cohort \\
\hline McGwin et al 2003 & Wet and dry AMD & Any agent & 6050 & Protective & Case control \\
\hline McGwin et al 2005 & $\begin{array}{l}\text { ARM and/or Wet } \\
\text { and dry AMD }\end{array}$ & Any agent & 12588 & Protective & Case control \\
\hline Smeeth et al & $\begin{array}{l}\text { ARM and/or Wet } \\
\text { and dry AMD }\end{array}$ & Any agent & 87969 & Not protective & Case control \\
\hline Friedman et al & Wet and dry AMD & Any agent & 148 & Protective & Case control \\
\hline Tan et al & Wet and dry AMD & Any agent & 2381 & Protective & Cohort \\
\hline McGwin et al 2006 & $\begin{array}{l}\text { ARM and/or Wet } \\
\text { and dry AMD }\end{array}$ & Any agent & 2755 & Not protective & Case control \\
\hline Drobec et al & Wet and dry AMD & Any agent & 214 & Protective & Case control \\
\hline Etminan et al & Wet and dry AMD & Any agent & 13335 & Not protective & Case control \\
\hline Maguire et al & $\begin{array}{l}\text { ARM and/or Wet } \\
\text { and dry AMD }\end{array}$ & Any agent & 744 & Not protective & Cohort \\
\hline Kaiserman et al & Wet AMD & Any agent & 139894 & Not protective & Case control \\
\hline Fong et al & Wet AMD & Any agent & 79369 & Inconclusive & Case control \\
\hline
\end{tabular}


and non-neovascular AMD in case-control ${ }^{11}$ as well as in population-based ${ }^{12}$ epidemiological studies. The vascular model proposes that the increase in intravascular pressure results from an increase in the post-capillary resistance of the choroid. As a result of the increased hydrostatic pressure within the underlying choroidal capillary network, lipid material accumulates in these sites from circulating blood and is laid down.

There is some evidence that the RPE is the source of lipids in Drusen and in Bruch's membrane. The vascular model proposes that impairment of choroidal perfusion compromises the processing of outer segment lipid by the RPE and the clearance of the lipoproteins secreted by the RPE. This results in Drusen, pigment changes, and geographic atrophy, as well as calcification and fracture of Bruch's membrane. Progressive accumulation of hydrophobic lipids in Bruch's membrane may compromise RPE function further by decreasing its hydraulic conductivity. ${ }^{13}$

The combination of elevated choriocapillary pressure breaks in Bruch's membrane and secretion of vascular endothelial growth factor (VEGF) causes choroidal neovascularization.

\section{The role of statins in AMD}

Statins modify patients' lipid profile and decrease their risk of coronary heart disease. They also prevent stroke and possibly, Alzheimer's disease. In recent studies it has been hypothesized that the anti-atherosclerotic properties of statins may protect against the development and progression of ARM to AMD. If we accept the vascular model proposed by Friedman then, as a consequence, it is intuitive to think that the reduction of the lipid load inside the vessels would benefit the overall compliance of the ocular tissues. In this way, statins may lead to a virtuous spiral of lower hydrostatic pressure and increased blood flow in the choroidal capillary network, resulting in a reduced tendency to deposit lipid in an atherosclerotic pattern within the eye.

Another property of statins is preservation of ischemic vasculature. ${ }^{14}$ The activation of a protein kinase results in an increased production of nitric oxide that results in an improved choroidal blood flow and a reduced capillary drop out.

Currently, there is intense research going on regarding the oxidative stress and AMD. Current evidence suggests that there should be a protective effect of statins against maculopathy because of their antioxidant activity. ${ }^{15}$ The continued intake of statins seem to be at least equal to the prophylactic antiARMD effect of multivitamin and antioxidant supplements, as expressed in the Blue Mountain Eye Study.
Statins have the capability of reducing the levels of C-reactive protein (CRP) and therefore mediate an antiinflammatory effect. ${ }^{16}$ It has been found that during AMD inflammatory cells that promote chronic inflammation are recruited. ${ }^{17}$ Therefore, by lowering the levels of CRP, statins may improve the inflammatory component of AMD.

\section{Current evidence}

The first study that investigated the aforementioned assumption was conducted in Italy by Martini et al in 1991. ${ }^{18}$ In this randomized clinical study, 30 participants with AMD were enrolled to receive simvastatin ( $20 \mathrm{mg} /$ day) or placebo for three months. The conclusion was that there was no statistically significant difference between the simvastatin and the placebo therapy in visual acuity. Unfortunately, this trial suffered methodological limitations such as the short duration of treatment and follow-up taking into account the slow progressive nature of the disease.

Subsequently, Della et $\mathrm{al}^{19}$ in an uncontrolled, nonrandomized clinical trial concluded that there was no significant difference in visual acuity between the patients taking statins and suffering from both raised cholesterol and signs of early non-neovascular macular degeneration respect the control group. Nonetheless, the study should be evaluated with caution as it was not controlled, which is considered as a major source of bias. For this reason, it has been excluded from the studies considered in the meta-analysis by Chuo et $\mathrm{al}^{20}$ relating to the subject.

In reference to the aforementioned analysis, this is the only effort to date to statistically analyze the current evidence on the presumed protective effects of the statins against AMD. In their analysis Chuo et al identified a considerable heterogeneity among the studies. They reached to the conclusion that the current evidence is not statistically strong because of the observational nature of the studies considered and that in order to reach valid statistical results we need long term interventional studies.

In 2001, Hall et $\mathrm{al}^{21}$ found in their study that those receiving statins had a reduced risk of age-related macular degeneration (after adjustment for coronary artery disease and smoking) compared to those not taking the drug. The odds ratio for macular degeneration was 0.14 with a wide confidence interval (0.02 to 0.83 ). In the same year, McCarty et $\mathrm{al}^{22}$ researched the association between statins and AMD in an elderly Australian population. They reported a lower rate of progression (3.6\% versus 13\%) of early AMD in those taking statins. Nonetheless, while the effect was large, it was not statistically significant. Delcourt et $\mathrm{al}^{23}$ continued in a 
population-based study on cataract and AMD and their risk factors concluding that there was no association between late onset of AMD and the use of hypocholesterolemic drugs.

In 2003 , three retrospective reviews ${ }^{24-26}$ of medical records reported that progression of AMD was slowed with statin use in a statistically significant manner. Nevertheless, three other population-based studies appeared during that period reporting that statins showed no protective effect. ${ }^{27-29}$ McGwin et $\mathrm{al}^{30}$ conducted a large clinical study that suggested that subjects with ARM were less likely to have filled a statin prescription.

In 2005, the same author in his study ${ }^{31}$ revealed a statistically significant relationship between AMD and the use of cholesterol-lowering medications. Smeeth et $\mathrm{al}^{32}$ in a population-based case-control study that used data from the United Kingdom General Practice Research Database, concluded that in the short and medium term statin use is not associated with a decreased risk of AMD. Friedman et $\mathrm{al}^{33}$ published a case-control study that was suggesting that patients on statins had a reduced risk of developing AMD.

In 2006, Tan et $\mathrm{al}^{34}$ published a cohort study (Blue Mountain Eye Study), and reached the conclusion that statin use was not associated with overall early AMD incidence but was protective for indistinct soft drusen, a key late AMD precursor lesion. McGwin et al returned with a new casecontrol study that used data from the Cardiovascular Health Study. ${ }^{35}$ The results suggested that no association existed between having used cholesterol-lowering medications and AMD. On the contrary, there was a suggestion that statin use might increase the risk of AMD.

Several important studies have been published on this subject in 2008. Drobec et $\mathrm{al}^{36}$ published a case-control study that concluded that use of statins may be a protective factor against age-related macular degeneration, since the percentage of statin users was much higher in the control group. Nonetheless, as a confirmation of the controversy over the efficacy or otherwise of statins in AMD, Etminan et $\mathrm{al}^{37}$ published another study in which it was concluded that statin use may be associated with an increase in the risk of AMD. A large study (Age-Related Maculopathy Statin Study, ARMSS) is currently being conducted by Guymer et al however, so far only the methodology has been published. ${ }^{38}$

In 2009, Kaiserman et $\mathrm{al}^{39}$ investigated the association between the use of statins and the risk for wet age-related macular degeneration. It was a case-control study that concluded that their use is not related to a reduced risk of wet AMD. The latest cohort study within a multicenter, randomized, clinical trial, the Complications of Age-related Macular Degeneration Prevention Trial (CAPT), was conducted by Maguire et al. ${ }^{40}$ They tried to evaluate the impact of statin use on the incidence of advanced age-related macular degeneration and its components, choroidal neovascularization (CNV) and geographic atrophy (GA), among patients with bilateral large drusen. The CAPT data are not consistent with a strong protective effect of statins on the development of advanced AMD among patients with bilateral large drusen.

In 2010 another case control study by Fong et $\mathrm{al}^{41}$ was inconclusive regarding whether the statin class of drug is protective against exudative age-related macular degeneration.

\section{Conclusion}

From the current evidence available, it is not safe to conclude upon the assumption of a protective effect of statins against ARM and AMD. This is because the clinical studies already conducted do not provide us with adequate data in order to draw certain conclusions. There is a need for large scale prospective studies with a long follow-up period and accurate assessment of AMD to further explore this matter. We are expecting the first results from the ARMSS study to help elucidate the controversy over the association between statin use and progression of age-related macular degeneration. Until then, physicians need to be vigilant in ensuring that use of statins remains restricted to the approved indications.

\section{Disclosure}

The authors report no conflicts of interest in this work.

\section{References}

1. Congdon NG, Friedman DS, Lietman T. Important causes of visual impairment in the world today. JAMA. 2003;290:2057-2060.

2. Fine SL, Maguire MG. It is not time to abandon radiotherapy for neovascular age-related macular degeneration. Arch Ophthalmol. 2001;119:275-276

3. Fine SL, Berger JW, Maguire MG, Ho AC. Age-related macular degeneration. $N$ Engl J Med. 2000;342:483-492.

4. Friedman E. The role of the atherosclerotic process in the pathogenesis of age-related macular degeneration. Am J Ophthalmol. 2000;130: 658-663.

5. Friedman E. A hemodynamic model of the pathogenesis of age-related macular degeneration. Am J Ophthalmol. 1997;124:677-682.

6. Friedman E, Smith TR, Kuwabara T. Senile choroidal vascular patterns and drusen. Arch Ophthalmol. 1963;69:220-230.

7. Malek G, Li CM, Guidry C, Medeiros NE, Curcio CA. Apolipoprotein $\mathrm{B}$ in cholesterol-containing drusen and basal deposits of human eyes with age-related maculopathy. Am J Pathol. 2003;162:413-425.

8. Dithmar S, Sharara NA, Curcio CA, et al. Murine high-fat diet and laser photochemical model of basal deposits in Bruch membrane. Arch Ophthalmol. 2001;119:1643-1649. 
9. Green WR, Enger C. Age-related macular degeneration histopathologic studies. The 1992 Lorenz E. Zimmerman Lecture. Ophthalmology. 1993;100:1519-1535.

10. Friedman E, Ivry M, Ebert E, Glynn R, Gragoudas E, Seddon J. Increased scleral rigidity and age-related macular degeneration. Ophthalmology. 1989;96:104-108.

11. Hyman L, Schachat AP, He Q, Leske MC. Hypertension, cardiovascular disease, and age-related macular degeneration. Age-Related Macular Degeneration Risk Factors Study Group. Arch Ophthalmol. 2000; 118:351-358.

12. van Leeuwen R, Ikram MK, Vingerling JR, Witteman JC, Hofman A, de Jong PT. Blood pressure, atherosclerosis, and the incidence of agerelated maculopathy: the Rotterdam Study. Invest Ophthalmol Vis Sci. 2003;44:3771-3777.

13. Bird AC, Marshall J. Retinal pigment epithelial detachments in the elderly. Trans Ophthalmol Soc U K 1986;105:674-682.

14. Kureishi Y, Luo Z, Shiojima I, et al. The HMG-CoA reductase inhibitor simvastatin activates the protein kinase Akt and promotes angiogenesis in normocholesterolemic animals. Nat Med. 2000;6:1004-1010.

15. Simons M. Molecular multitasking: statins lead to more arteries, less plaque. Nat Med. 2000;6:965-966.

16. Albert MA, Danielson E, Rifai N, Ridker PM. Effect of statin therapy on $\mathrm{C}$-reactive protein levels: the pravastatin inflammation/CRP evaluation (PRINCE): a randomized trial and cohort study. JAMA 2001;286:64-70.

17. Penfold PL, Killingsworth MC, Sarks SH. Senile macular degeneration: the involvement of immunocompetent cells. Graefes Arch Clin Exp Ophthalmol. 1985;223:69-76.

18. Martini E, Scorolli L, Burgagni MS, Fessehaie S. Valutazione degli effetti retinici della somministrazione di simvastatina in pazienti affetti da degenerazione maculare senile. Annali Di Ottalmologia e Clinica Oculistica. 1991;117:1121-1126.

19. Della V, Scorolli L, Meduri R. Retinal effects of simvastatin in patients affected by age related macular degeneration. Annali Di Ottalmologia e Clinica Oculistica. 2000;126:89-95.

20. Chuo JY, Wiens M, Etminan M, Maberley DA. Use of lipid-lowering agents for the prevention of age-related macular degeneration: a meta-analysis of observational studies. Ophthalmic Epidemiol. 2007; $14: 367-374$.

21. Hall NF, Gale CR, Syddall H, Phillips DI, Martyn CN. Risk of macular degeneration in users of statins: cross sectional study. BMJ. 2001;323: 375-376.

22. McCarty CA, Mukesh BN, Guymer RH, Baird PN, Taylor HR. Cholesterol-lowering medications reduce the risk of age-related maculopathy progression. Med J Aust. 2001;175:340.

23. Delcourt C, Michel F, Colvez A, Lacroux A, Delage M, Vernet MH. Associations of cardiovascular disease and its risk factors with agerelated macular degeneration: the POLA study. Ophthalmic Epidemiol. 2001;8:237-249.

24. Chavis PS, Castillo IG, Schwartz SG, et al. Risk factors for age-related macular degeneration. Invest Ophthalmol Vis Sci. 2003:5038.

25. Wilson H, Bhatt HRF, Schwartz DM, et al. Statin therapy is associated with decreased odds of developing neovascular age-related macular degeneration. Invest Ophthalmol Vis Sci. 2003:1804.
26. Wilson HL, Schwartz DM, Bhatt HR, McCulloch CE, Duncan JL. Statin and aspirin therapy are associated with decreased rates of choroidal neovascularization among patients with age-related macular degeneration. Am J Ophthalmol. 2004;137:615-624.

27. Klein R, Klein BE, Tomany SC, Danforth LG, Cruickshanks KJ. Relation of statin use to the 5-year incidence and progression of agerelated maculopathy. Arch Ophthalmol. 2003;121:1151-1155.

28. Klein R, Knudtson MD, Klein BE. Statin use and the five-year incidence and progression of age-related macular degeneration. Am J Ophthalmol. 2007;144:1-6

29. van Leeuwen R, Vingerling JR, Hofman A, de Jong PT, Stricker BH. Cholesterol lowering drugs and risk of age related maculopathy: prospective cohort study with cumulative exposure measurement. $B M J$. 2003;326:255-256.

30. McGwin G Jr, Owsley C, Curcio CA, Crain RJ. The association between statin use and age related maculopathy. Br J Ophthalmol. 2003;87:1121-1125.

31. McGwin G Jr, Xie A, Owsley C. The use of cholesterol-lowering medications and age-related macular degeneration. Ophthalmology. 2005; 112:488-494.

32. Smeeth L, Cook C, Chakravarthy U, Hubbard R, Fletcher AE. A case control study of age related macular degeneration and use of statins. Br J Ophthalmol. 2005;89:1171-1175.

33. Friedman E, Rigas IK, Makar M. The relationship of statin use to the development of age-related macular degeneration. IOVS 2005;46:199.

34. Tan JS, Mitchell P, Rochtchina E, Wang JJ. Statins and the long-term risk of incident age-related macular degeneration: the Blue Mountains Eye Study. Am J Ophthalmol. 2007;143:685-687.

35. McGwin G Jr, Modjarrad K, Hall TA, Xie A, Owsley C. 3-hydroxy3-methylglutaryl coenzyme a reductase inhibitors and the presence of age-related macular degeneration in the Cardiovascular Health Study. Arch Ophthalmol. 2006;124:33-37.

36. Drobek-Slowik M, Karczewicz D, Safranow K, Jakubowska K, Chlubek D. Use of statins as a form of protection against age-related macular degeneration (AMD). Klin Oczna. 2008;110:50-54.

37. Etminan M, Brophy JM, Maberley D. Use of statins and angiotensin converting enzyme inhibitors (ACE-Is) and the risk of age-related macular degeneration: nested case-control study. Curr Drug Saf. 2008;3: 24-26.

38. Guymer RH, Dimitrov PN, Varsamidis M, et al. Can HMG Co-A reductase inhibitors ("statins") slow the progression of age-related macular degeneration? The age-related maculopathy statin study (ARMSS). Clin Interv Aging. 2008;3:581-593.

39. Kaiserman N, Vinker S, Kaiserman I. Statins do not decrease the risk for wet age-related macular degeneration. Curr Eye Res. 2009;34: 304-310.

40. Maguire MG, Ying GS, McCannel CA, Liu C, Dai Y. Statin Use and the Incidence of Advanced Age-Related Macular Degeneration in the Complications of Age-Related Macular Degeneration Prevention Trial. Ophthalmology. 2009

41. Fong DS, Contreras R. Recent statin use and 1-year incidence of exudative age-related macular degeneration. Am J Ophthalmol. 149: 955-958.
Clinical Ophthalmology

\section{Publish your work in this journal}

Clinical Ophthalmology is an international, peer-reviewed journal covering all subspecialties within ophthalmology. Key topics include: Optometry; Visual science; Pharmacology and drug therapy in eye diseases; Basic Sciences; Primary and Secondary eye care; Patient Safety and Quality of Care Improvements. This journal is indexed on Submit your manuscript here: http://www.dovepress.com/clinical-ophthalmology-journal

\section{Dovepress}

PubMed Central and CAS, and is the official journal of The Society of Clinical Ophthalmology (SCO). The manuscript management system is completely online and includes a very quick and fair peer-review system, which is all easy to use. Visit http://www.dovepress.com/ testimonials.php to read real quotes from published authors. 